\section{Resistance of Greenhouse, Laboratory, and Native Populations of Western Flower Thrips to Spinosad}

\author{
Rebecca L. Loughner, ${ }^{1}$ Daniel F. Warnock, ${ }^{2}$ and Raymond A. Cloyd ${ }^{3}$ \\ University of Illinois at Urbana-Champaign, Department of Natural Resources \\ and Environmental Sciences, 1201 South Dorner Drive, Urbana, IL 61801
}

Additional index words. Conserve, transvaal daisy, resistance, insecticides

\begin{abstract}
Western flower thrips (Frankliniella occidentalis (Pergande) (Thysanoptera: Thripidae)] collected from greenhouse, laboratory, and native populations were evaluated for resistance to the insecticide spinosad. Individual cut stems of transvaal daisy (Gerbera jamesonii $\mathrm{H}$. Bolus ex Hook. f.) were inoculated with 25 adults from 1 of 9 thrips populations and maintained in isolation chambers. Treatments of no spray, water spray, spinosad at one-half label rate $\left(0.41 \mathrm{~mL} \cdot \mathrm{L}^{-1}\right)$ and spinosad at the recommended label rate $\left(0.81 \mathrm{~mL} \cdot \mathrm{L}^{-1}\right)$ were applied to the flowers. Three days after treatment, the number of live and dead thrips was recorded. Significantly more thrips were recovered from the control treatments than the spinosad treatments. Thrips survival varied by treatment and insect population. Based on an odds ratio analysis, the likelihood of recovering live thrips was greater in the IL-GH1 (Illinois greenhouse) population than in the NV-N1 (Nevada native) reference population for both spinosad treatments, suggesting resistance to spinosad in the IL-GH1 population. The IL-GH1 population was collected from a greenhouse regularly sprayed with spinosad whereas the NV-N1 population was collected in Incline Village, Nev., on wildflowers with no history of exposure to spinosad. This is the first documented indication of spinosad resistance in a thrips population. In comparison to the NV-N1 reference population, none of the populations collected from laboratory or native nonagricultural environments exhibited evidence of resistance to spinosad. Resistance to an insecticide with a novel mode of action, such as spinosad, indicates the necessity of rotating insecticides and implementing alternative methods of managing western flower thrips. Chemical names used: spinosad including spinosyn A and spinosyn D (Conserve SC).
\end{abstract}

Western flower thrips [Frankliniella occidentalis (Pergande)], is a major pest of floricultural crops worldwide (Lewis, 1997) and is typically controlled with insecticides (Parrella, 1995). The tolerance for western flower thrips in production environments is low, as the insect reduces the aesthetic value of ornamentals and vectors impatiens necrotic spot virus and tomato spotted wilt virus (Ullman et al., 1997). Thrips nymphs and adults feed inside crevices of flowers and developing foliage making it difficult to contact them with insecticides which reduces the effectiveness of chemical treatment. The life cycle of western flower thrips, which lasts from 15 to $44 \mathrm{~d}$ depending on temperature (Lublinkhof and

Received for publication 7 July 2003. Accepted for publication 20 June 2004. This research was supported in part by USDA CRIS Hatch Project ILLU-65-0308 and the Fred C. Gloeckner Foundation. The authors would like to thank Stephanie Larsen and Andreana Lau for their assistance with this research and David A. Nickle, USDA Systematic Entomology Laboratory, Beltsville, Md., for the identification of thrips species used in this project. Mention of a trademark, proprietary product, or vendor does not constitute a guarantee or warranty of the product and does not imply its approval to the exclusion of other products or vendors that may also be suitable.

${ }^{1}$ Graduate student. Current address: Department of Entomology, NYSAES, Cornell University, Geneva, NY 14456.

${ }^{2}$ Associate professor, To whom correspondence should be addressed.

${ }^{3}$ Assistant professor
Foster 1977), allows for multiple generations per year in greenhouses. The need for repeated applications from a limited number of insecticides labeled for western flower thrips, combined with a short generation time, creates a high level of selection pressure and a situation in which thrips are likely to become resistant to insecticides (Broadbent and Pree, 1997; Brødsgaard ,1994; Immaraju et al., 1992; Zhao et al., 1995).

Salgado (1998) reviewed the activity of spinosad and described the physiological effects of spinosyns, the active components in spinosad derived from the soil actinomycete Saccharopolyspora spinosa. Spinosyns, which are active on mites and several insect orders including Thysanoptera, work by exciting neurons in the central nervous system and causing involuntary muscle contractions, ultimately paralyzing the insect due to neuromuscular fatigue (Salgado, 1998). Salgado (1998) also reported that spinosad has no significant effect on typical insect and drug target sites, indicating a novel mode of action. Resistance to spinosad has been reported in populations of diamondback moth (Plutella xylostella L.), beet armyworm (Spodoptera exigua Hübner), and tobacco budworm (Heliothis virescens Fabricius) (Moulton et al., 2000; Roe et al., 2000; Wyss et al., 2003; Young et al., 2003; Zhao et al., 2002). High selection pressure due to excessive insecticide use coupled with multiple insect generations per year increase the possibility of insect populations developing resistance to specific insecticides (Immaraju et al., 1992).

Spinosad effectively controls western flower thrips in greenhouses (Cloyd and Sadof, 2000; Eger et al., 1998) and since commercialization in 1998 has become a common insecticide used to manage western flower thrips in greenhouses. In fact, many greenhouse managers rely almost exclusively on this compound, which increases the potential for thrips populations to develop resistance. Currently there is no evidence of field resistance to spinosad within western flower thrips populations. As a result, the purpose of this study was to determine if thrips populations sampled from greenhouses, laboratories, and native environments demonstrate resistance to spinosad.

\section{Materials and Methods}

A completely randomized design with five replications was used to evaluate four spray treatments on nine different populations of thrips. Thrips for this study were collected from July to December 2001 at locations across the U.S. including greenhouses, laboratories, and native habitats. In total, 19 thrips populations were acquired with 9 populations being selected for this experiment (Table 1). These nine populations were chosen based on the geographic collection location, potential range of exposure to spinosad, and overall population size after rearing for 4 months under laboratory conditions. All populations were identified as western flower thrips except the CA-GH1 population, which was composed of western flower thrips and an unidentified thrips species (DavidA. Nickle, USDA Systematic Entomology Laboratory, Beltsville, Md.). Because all thrips on a greenhouse crop are considered pests, this population remained in the study. The NV-N1 population was considered a susceptible reference population because it was the most isolated population collected from a nonagricultural area and most likely had not been treated with spinosad. On 11 July 2001, laboratory colonies were established for seven of the nine test populations. The IL-LC1 and TX-GH1 populations were established in 1998 and on 24 May 2001, respectively. Thrips colonies were maintained in isolation for 4 months in environmental chambers (Conviron E15, Controlled Environments, Pembina, N.D.) set at $26 \pm 2{ }^{\circ} \mathrm{C}$ and $75 \%$ relative humidity, with a 16/8-h (light/dark) photoperiod provided by fluorescent and incandescent lamps. Rearing cages were $40 \times 27.5 \times 22.5$-cm plastic storage containers (Rubbermaid, Wooster, Ohio.) vented with $135-\mu \mathrm{m}$ thrips screening (Greenthumb Group, Downers Grove, Ill.). A 3-cm layer of calcined clay ( 8 to $16 \mathrm{~mm}$, Jongkind B.V. Hydro, Holland) and a 1.5-cm layer of deionized water were placed in the bottom of the cage to maintain high humidity. Green bean (Phaseolus vulgaris L.) pods, dilute honey, and cut asters (Callistephus chinensis L. Nees.) were provided as food sources and oviposition sites. These were placed inside the rearing cages in a $36 \times 25.5 \times 14.5-\mathrm{cm}$ poly mesh utility basket (United Plastics, Leominster, Mass., or Sterilite, Townsend, Mass.). 
Table 1. Western flower thrips populations collected from native $(\mathrm{N})$, greenhouse $(\mathrm{GH})$, or laboratory colony (LC) populations in five states throughout the U.S. that were evaluated for resistance to spinosad.

\begin{tabular}{lll}
\hline Population & Collection location & Host plant \\
\hline NV-N1 & Incline Village, Nev. & Wildflowers \\
NV-N2 & Carson, Nev. & Wildflowers \\
CA-N2 & Salinas, Calif. & Osteospermum (Osteospermum ecklonis L.) \\
CA-GH1 & Salinas, Calif. & Carnations (Dianthus caryophyllus L.) \\
IL-GH1 & Urbana, Ill. & Transvaal daisy (Gerbera jamesonii H. Bolus ex. Hook. f.) \\
IL-LC1 & Urbana, Ill. & Green bean pods and seedlings (Phaseolus vulgaris L.) \\
TX-GH1 & Tyler, Texas & Rose (Rosa species L.) \\
TX-LC1 & College Station, Texas & Lima bean leaves (Phaseolus limensis var. limenanus L.H. Bailey) \\
MA-LC1 & Amherst, Mass. & Kidney bean (Phaseolus vulgaris L.) \\
\hline
\end{tabular}

${ }^{2}$ The notation NV-N1 represents the initial population of thrips collected from a native habitat in Nevada. Subsequent populations collected from the same state and habitat type are sequentially numbered.

yPopulations were collected from multiple flowering species in a nonagricultural area.

Cut transvaal daisy (Gerbera jamesonii $\mathrm{H}$. Bolus ex Hook. f.) stems were purchased from a wholesale broker (Four Seasons, Litchfield, Ill.). Spray records from the commercial greenhouse where the transvaal daisy flowers were produced indicated that no pesticides had been applied for the 2-week period before harvest and that spinosad had not been applied for at least $30 \mathrm{~d}$. Thus, the possibility of pesticide residues negatively affecting thrips survival in this experiment was minimal. Tissue (5 to $8 \mathrm{~cm}$ ) was removed from the end of each stem. Individual flower stems were placed in floral preservative $\left(9.5 \mathrm{~g} \cdot \mathrm{L}^{-1}\right.$ deionized water, Floralife, Walterboro, S.C.) and kept at room temperature (20 to $24{ }^{\circ} \mathrm{C}$ ) for 2 to $3 \mathrm{~h}$ for the stems to take up preservative. They were moved to a cooler set at $3 \pm 1{ }^{\circ} \mathrm{C}$ and constantly illuminated with fluorescent lamps. Immediately before use, stems were cut to a uniform length of $33 \mathrm{~cm}$, placed in fresh floral preservative, and returned to the cooler.

Isolation cages for the cut flowers consisted of a $12.7-\mathrm{cm}(1.2-\mathrm{L})$ plastic pot, a $0.95-\mathrm{L}$ reservoir for floral preservative, and a screened cage $[62 \times 12$-cm diameter with $135-\mu m$ thrips screening (Greenthumb Group, Inc., Downers Grove, Ill.) covering the vents] to prevent thrips escape (Fig. 1). A 0.95-L clear plastic cup with a lid (Solo Cup Co., Urbana, Ill.) was filled with floral preservative $\left(9.5 \mathrm{~g} \cdot \mathrm{L}^{-1}\right.$ deionized water) and placed inside an empty $12.7-\mathrm{cm}$ (1.2-L) pot. The space between the cup and the pot was filled with soilless mix (SB300 Universal; Sun Gro Horticulture, Bellevue, Wash.) to stabilize the cup and support the screened cage. A transvaal daisy stem was inserted through the opening in the cup lid to maintain the flower in an upright position. The screened cage was placed into the soil inside the rim of the pot. Three 1.2-cm holes in the screened cage, each sealed with a rubber stopper (No. 00), provided ports to insert a sprayer nozzle for applying the designated treatments (Fig. 1).

Each transvaal daisy flower either remained as a noninoculated control or was inoculated with 25 adults (mixture of males and females) from one of the nine thrips populations. Thrips were collected into $20-\mathrm{mL}$ glass vials using a modified aspirator (Cloyd et al., 2001). Vials were opened and tapped so that the thrips were placed onto the center of each flower. The vial and lid were placed on the $0.95-\mathrm{L}$ cup lid to allow any remaining thrips to migrate out of the vial. The screened cage was placed over the flower and the cage was sealed to the pot using a strip of 5-cm wide tape (Fig. 1). A total of 500 thrips from each population were used to inoculate the flowers.

Two days following inoculation, one of four treatments was applied to each transvaal daisy flower: no spray, water spray, spinosad (Conserve SC; DowAgroSciences, Indianapolis, Ind.) at one-half the label rate $\left(0.41 \mathrm{~mL} \cdot \mathrm{L}^{-1}\right)$ and the recommended label rate $\left(0.81 \mathrm{~mL} \cdot \mathrm{L}^{-1}\right)$. Flowers were sprayed from all angles for about 10-s with a 4 L compressed air sprayer, applying $25 \mathrm{~mL}$ of spray solution per flower. In total, 200 flowers $(20$ flowers $\times 9$ thrips populations +20 flowers $\times 1$ noninoculated control) were divided evenly between the four spray treatments replicated five times to arrive at five flowers per treatment combination. Thus, each inoculated flower contained 25 western flower thrips from one of nine populations (20 flowers $\times 25$ western flower thrips $=500$ western flower thrips per population). Flowers were dissected $3 \mathrm{~d}$ after treatment and the number of live and dead thrips was recorded. A few flowers developed a fungal disease after treatments were applied that significantly compromised flower stem integrity. To mitigate any confounding effects on thrips survival due to this fungal pathogen and subsequent flower degradation, these flowers were excluded from the analysis. Thus, CA-GH $1 \times$ spinosad 0.41 $\mathrm{mL} \cdot \mathrm{L}^{-1}, \mathrm{MA}-\mathrm{LC} 1 \times$ spinosad $0.81 \mathrm{~mL} \cdot \mathrm{L}^{-1}$, $\mathrm{CA}-\mathrm{N} 2 \times$ spinosad $0.81 \mathrm{~mL} \cdot \mathrm{L}^{-1}, \mathrm{CA}-\mathrm{N} 2 \times$ no spray, and MA-LC1 $\times$ water were represented by four replications and MA-LC $1 \times$ no spray was represented by three replications.

A logistic regression model based on a binomial distribution and logit link was used to examine the main effects, thrips population and spray treatment, based on the odds of recovering live thrips from each population compared to the NV-N1 reference population (SAS Institute, Inc., Cary, N.C.). The odds ratio was used to assess the risk of a particular outcome (resistance) if a certain factor (insecticide use) was present. The odds ratio is a relative measure of risk, indicating how much more likely it is that a population exposed to the factor will develop the outcome compared to a population not exposed to the factor. The odds of the outcome occurring is the probability that the outcome will occur divided by the probability that the outcome will not occur. The odds ratio is then used to compare the odds for two groups and is calculated by dividing the odds in group one by the odds in a second group (the reference). As a result, the odds ratio gives the ratio of the odds of suffering some type of fate. This procedure takes values between zero and infinity with one being the value where there is no difference between the groups compared. An odds ratio larger than one means that group one has a larger proportion of individuals that suffered some outcome than the reference group; however, if the opposite is true, the odds ratio will be smaller than one. The closer the value is to zero or infinity, the greater the difference between

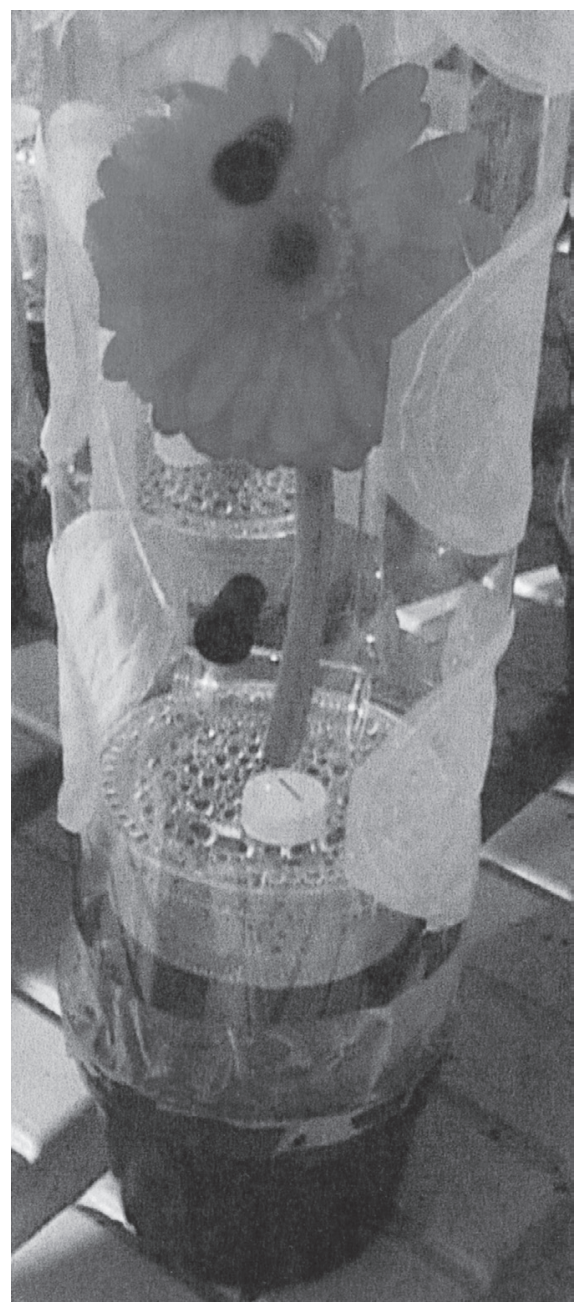

Fig. 1. Isolation cage for evaluating insecticide resistance in populations of western flower thrips on cut flowers. 
Table 2. Odds ratio estimates for total number of western flower thrips recovered for spray treatments and populations using the water spray control or the NV-N1 population as the reference for treatment or population, respectively.

\begin{tabular}{llcc}
\hline Parameter & $\mathrm{n}$ & $\begin{array}{c}\text { Mean } \pm \text { SE } \\
\text { of thrips recovered }\end{array}$ & Odds ratio $^{\mathrm{z}}$ \\
\hline $\begin{array}{l}\text { Treatment } \\
\text { Spinosad }\end{array}$ & & & \\
$\quad 0.81 \mathrm{~mL} \cdot \mathrm{L}^{-1}$ & 48 & $10.0 \pm 0.9$ & $0.49(0.41,0.58)^{\mathrm{y}}$ \\
$\quad 0.41 \mathrm{~mL} \cdot \mathrm{L}^{-1}$ & 49 & $11.1 \pm 0.7$ & $0.59(0.50,0.70)$ \\
No spray & 47 & $14.3 \pm 0.9$ & $1.06(0.89,1.26)$ \\
Water & 49 & $14.3 \pm 1.1$ & \\
Population & & & $0.56(0.43,0.72)$ \\
NV-N2 & 20 & $12.2 \pm 1.3$ & $0.49(0.37,0.63)$ \\
CA-N2 & 18 & $11.1 \pm 0.9$ & $0.64(0.49,0.82)$ \\
CA-GH1 & 19 & $12.9 \pm 1.5$ & $0.67(0.52,0.87)$ \\
IL-GH1 & 20 & $13.3 \pm 1.2$ & $0.74(0.57,0.95)$ \\
IL-LC1 & 20 & $13.9 \pm 1.2$ & $0.79(0.61,1.02)$ \\
TX-GH1 & 20 & $14.6 \pm 1.5$ & $1.00(0.77,1.30)$ \\
TX-LC1 & 20 & $15.8 \pm 1.2$ & $0.87(0.66,1.14)$ \\
MA-LC1 & 16 & $14.6 \pm 1.0$ & \\
NV-N1 & 20 & $15.7 \pm 1.2$ & \\
\hline
\end{tabular}

${ }^{\mathrm{z}}$ Odds ratio estimate. The odds ratio is used to assess the risk of a particular outcome (resistance) if a certain factor (insecticide use) is present. Thus, the odds ratio is a relative measure of risk, telling one how much more likely it is that a population exposed to the factor will develop the outcome compared to a population not exposed to the factor. The odds of an outcome occurring is the probability that the outcome will occur divided by the probability that the outcome will not occur. The odds ratio is used to compare the odds for two groups and is calculated by dividing the odds in group one by the odds in a second reference group. Thus, the odds ratio gives the ratio of the odds of suffering some fate. An odds ratio larger than one means that group one has a larger proportion of individuals that suffered some outcome than the reference group; however, if the opposite is true the odds ratio will be smaller than one. The closer the value is to zero or infinity the greater the difference between group one and the reference group.

y95\% Wald confidence interval.

group one and the reference group. While relative risks are easier to interpret, relative risks and odds are similar when the outcome events are rare, such as resistance in an insect population. The odds ratio and relative risks are less correlated when outcome events are common. One major advantage of the odds ratio over relative risks is that the odds ratio is more closely related to frequently used statistical techniques such as logistic regression than risk ratio analysis (Westergren et al., 2001). This makes data analysis more concise and results more robust.

Due to the binomial nature of the data, the odds of survival for each population were calculated by comparing the probability of survival to the probability of mortality. Odds ratios were used to determine if the number of live thrips recovered from each population was significantly different from the reference population, NV-N1, within each treatment. The NV-N1 population was chosen as the susceptible reference population because it was geographically isolated from agricultural environments where spinosad may have been used to manage thrips. For certain combinations of thrips populations and spinosad treatments, no live thrips were recovered from the five replications. The total number of live thrips recovered for each thrips population by treatment combination, including those with nonzero counts, was increased by 0.5 to permit calculation of the odds ratios (Agresti, 2002).

\section{Results and Discussion}

The noninoculated flower controls were included in this study to ensure that the transvaal daisy flowers used were not contaminated with thrips before treatment. An average of $0.6 \pm 0.2$ (mean $\pm \mathrm{SE}$ ) thrips were recovered from six of the noninoculated flowers with individual flowers having up to three thrips. This indicates that the number of thrips present in the flowers before inoculation was minimal and did not affect the results. Therefore, the noninoculated control was excluded from the analysis.
The total number of thrips (live + dead) recovered was highly influenced by both treatment $($ chi-square $=114.08, \mathrm{df}=3, P<0.0001)$ and population (chi-square $=56.01, \mathrm{df}=8, P$ $<0.0001)$. The no spray control and the water spray were not significantly different based on the total number of thrips recovered (Table 2). Thrips were less likely to be recovered in the one-half label treatment (between $30 \%$ and $50 \%$ ) and in the label treatment (between $42 \%$ and $59 \%$ ) compared to the water spray control (Table 2). A 95\% confidence interval for the odds ratio estimate that does not include the value one indicates a significant difference in the odds of thrips being recovered between the compared treatments. Many thrips in the insecticide treated flowers were dead and desiccated, whereas most thrips in the control treatments were alive and mobile. The lower number of thrips found in the insecticide treated flowers may be due to dead thrips falling out of the flowers before harvesting. Dead thrips were not found on the lids of the cups directly under the flowers; however, the surface of the potting media supporting the floral preservative reservoir was not examined.

Averaged across all treatments, the odds of finding thrips in the IL-LC1, CA-GH1, NV-N2, IL-GH1, and CA-N2 populations were significantly less than in the NV-N1 reference population (Table 2). There is no apparent reason as to why fewer thrips were recovered from these populations than the NV-N1 reference population. While size may impact recovery percentage of smaller thrips as they are more difficult to locate, individual thrips lengths were not measured in this study. All flowers were completely dissected and thoroughly examined to minimize error during data collection.

Analysis confirmed that the NV-N1 population had no live thrips recovered from spinosad treated flowers (Table 3). This is significant as the NV-N1 population was chosen as the susceptible population for conducting the odds ratio analysis. Had thrips in this population survived, the use of this population as a susceptible population in odds ratio analysis would have resulted in unreliable information.

In contrast, live thrips from several populations were recovered in the treatments in which spinosad was applied (Table 3 ). At the recommended label rate of spinosad, $20.4 \%$ of the recovered thrips from the IL-GH1 popula-

Table 3. Mean ( \pm SE) number of western flower thrips recovered in each population within each of four spray treatments.

\begin{tabular}{|c|c|c|c|c|c|c|c|c|}
\hline \multirow[b]{2}{*}{ Population } & \multicolumn{8}{|c|}{ Spray treatment } \\
\hline & No spray & Water & $\begin{array}{l}\text { Spinosad at } \\
0.41 \mathrm{~mL} \cdot \mathrm{L}^{-1}\end{array}$ & $\begin{array}{l}\text { Spinosad at } \\
0.81 \mathrm{~mL} \cdot \mathrm{L}^{-1}\end{array}$ & No spray & Water & $\begin{array}{l}\text { Spinosad at } \\
0.41 \mathrm{~mL} \cdot \mathrm{L}^{-1}\end{array}$ & $\begin{array}{l}\text { Spinosad at } \\
0.81 \mathrm{~mL} \cdot \mathrm{L}^{-1}\end{array}$ \\
\hline & \multicolumn{4}{|c|}{ Total thrips recovered (no.) $)^{\mathrm{z}}$} & \multicolumn{4}{|c|}{ Live thrips recovered (no.) ${ }^{\mathrm{z}}$} \\
\hline NV-N1 & $18.6 \pm 2.2$ & $17.0 \pm 1.4$ & $12.4 \pm 2.4$ & $14.6 \pm 2.7$ & $16.4 \pm 1.9$ & $15.2 \pm 1.4$ & $0.0 \pm 0.0$ & $0.0 \pm 0.0$ \\
\hline NV-N2 & $14.4 \pm 2.7$ & $14.6 \pm 2.4$ & $9.8 \pm 2.2$ & $10.0 \pm 3.1$ & $12.2 \pm 2.3$ & $13.2 \pm 2.7$ & $0.0 \pm 0.0$ & $0.4 \pm 0.2$ \\
\hline CA-N2 & $13.5 \pm 2.1$ & $12.8 \pm 1.1$ & $10.6 \pm 1.4$ & $7.0 \pm 1.2$ & $12.3 \pm 1.7$ & $10.8 \pm 1.0$ & $0.4 \pm 0.4$ & $0.0 \pm 0.0$ \\
\hline CA-GH1 & $15.6 \pm 0.7$ & $16.2 \pm 4.7$ & $11.5 \pm 2.0$ & $8.4 \pm 2.0$ & $13.6 \pm 0.7$ & $12.8 \pm 4.2$ & $1.3 \pm 0.3$ & $0.0 \pm 0.0$ \\
\hline IL-GH1 & $15.6 \pm 2.5$ & $12.8 \pm 2.6$ & $14.0 \pm 1.0$ & $10.8 \pm 3.1$ & $12.8 \pm 1.3$ & $10.8 \pm 2.5$ & $2.2 \pm 0.4$ & $2.2 \pm 0.6$ \\
\hline IL-LC1 & $15.2 \pm 0.5$ & $17.0 \pm 2.6$ & $9.6 \pm 1.5$ & $13.6 \pm 3.0$ & $13.2 \pm 1.2$ & $16.0 \pm 3.0$ & $0.0 \pm 0.0$ & $0.2 \pm 0.2$ \\
\hline TX-GH1 & $16.0 \pm 2.9$ & $18.6 \pm 4.2$ & $12.2 \pm 2.5$ & $11.4 \pm 1.8$ & $13.8 \pm 2.9$ & $15.0 \pm 3.6$ & $0.0 \pm 0.0$ & $0.0 \pm 0.0$ \\
\hline TX-LC1 & $17.6 \pm 2.8$ & $20.6 \pm 2.1$ & $14.6 \pm 1.0$ & $10.2 \pm 1.2$ & $13.4 \pm 2.1$ & $18.2 \pm 1.6$ & $0.4 \pm 0.4$ & $0.0 \pm 0.0$ \\
\hline MA-LC1 & $17.3 \pm 2.3$ & $12.0 \pm 1.4$ & $15.6 \pm 2.5$ & $14.0 \pm 1.1$ & $13.0 \pm 1.2$ & $9.25 \pm 1.0$ & $0.2 \pm 0.2$ & $0.3 \pm 0.3$ \\
\hline
\end{tabular}

${ }^{2} \mathrm{n}=5$ for each treatment combination, except CA-GH1 $\times \operatorname{spinosad} 0.41 \mathrm{~mL} \cdot \mathrm{L}^{-1}, \mathrm{MA}-\mathrm{LC} 1 \times \operatorname{spinosad} 0.81 \mathrm{~mL} \cdot \mathrm{L}^{-1}, \mathrm{CA}-\mathrm{N} 2 \times \mathrm{spinosad} 0.81 \mathrm{~mL} \cdot \mathrm{L}^{-1}, \mathrm{CA}-\mathrm{N} 2 \times \mathrm{no}$ spray, and MA-LC1 $\times$ water where $n=4$ and MA-LC1 $\times$ no spray where $n=3$. 
Table 4. Odds ratios for recovering live western flower thrips in each population compared to the NV-N1 reference population within each of four spray treatments.

\begin{tabular}{|c|c|c|c|c|}
\hline \multirow[b]{2}{*}{$\begin{array}{l}\text { Thrips } \\
\text { population }\end{array}$} & \multicolumn{4}{|c|}{ Treatment } \\
\hline & No spray & Water & $\begin{array}{l}\text { Spinosad half-label rate } \\
0.41 \mathrm{~mL} \cdot \mathrm{L}^{-1}\end{array}$ & $\begin{array}{c}\text { Spinosad label rate } \\
0.81 \mathrm{~mL} \cdot \mathrm{L}^{-1}\end{array}$ \\
\hline NV-N2 & $0.75^{\mathrm{z}}(0.04,12.97)^{\mathrm{y}}$ & $1.10(0.06,19.75)$ & $1.26(0.03,64.92)$ & $7.58(0.35,161.99)$ \\
\hline $\mathrm{CA}-\mathrm{N} 2$ & $1.25(0.07,23.31)$ & $0.64(0.04,11.29)$ & $6.07(0.28,129.63)$ & $2.01(0.04,103.90)$ \\
\hline CA-GH1 & $0.91(0.05,15.89)$ & $0.46(0.03,7.80)$ & $12.85(0.69,238.52)$ & $1.73(0.03,89.06)$ \\
\hline IL-GH1 & $0.62(0.04,10.65)$ & $0.64(0.04,11.29)$ & $24.16(1.39,420.50)$ & $38.86(2.22,679.21)$ \\
\hline IL-LC1 & $0.88(0.05,15.43)$ & $1.82(0.10,33.60)$ & $1.29(0.03,66.27)$ & $3.27(0.13,81.91)$ \\
\hline TX-GH1 & $0.84(0.05,14.64)$ & $0.51(0.03,8.61)$ & $1.02(0.02,52.15)$ & $1.28(0.03,65.63)$ \\
\hline TX-LC1 & $0.44(0.03,7.40)$ & $0.91(0.05,15.69)$ & $4.37(0.21,93.05)$ & $1.43(0.03,73.35)$ \\
\hline MA-LC1 & $0.41(0.02,7.08)$ & $0.40(0.02,7.10)$ & $2.42(0.10,60.60)$ & $3.97(0.16,99.81)$ \\
\hline
\end{tabular}

${ }^{2}$ Odds ratio estimate. The odds ratio is used to assess the risk of a particular outcome (resistance) if a certain factor (insecticide use) is present. Thus, the odds

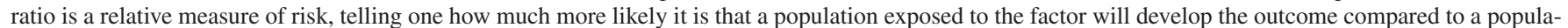

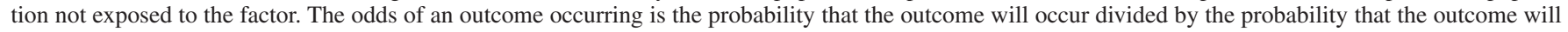

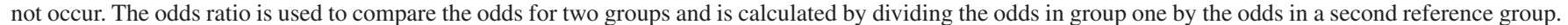

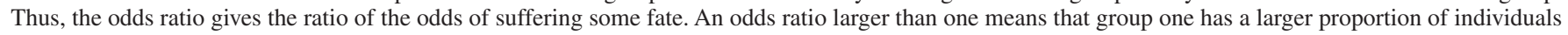

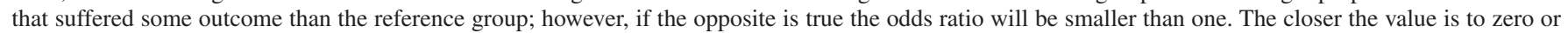
infinity the greater the difference between group one and the reference group.

y $95 \%$ Wald confidence interval.

tion were alive. The odds ratios of live thrips being recovered in each population compared to the NV-N1 population within a treatment are shown in Table 4. The odds of thrips surviving at one-half the label rate and the recommended label rate are greater for the IL-GH1 population than the NV-N1 reference population (Table 3). Although the confidence intervals were large, which often is the case with odds ratio analysis, intervals for neither the 0.41 nor the $0.81 \mathrm{~mL} \cdot \mathrm{L}^{-1}$ spinosad treatments include one, indicating that thrips in the IL-GH1 population had greater odds of being recovered alive than thrips in the NV-N1 population. None of the populations was significantly different from the reference population in the control treatments, suggesting that it is unlikely that the fitness of the populations was responsible for the greater odds of survival in spinosad treatments for the IL-GH1 population. The confidence intervals of the odds ratio for all other thrips populations in both spinosad treatments showed no differences between survival in each respective population and the NV-N1 population, indicating the increased odds of survival in the IL-GH1 population were due to the presence of resistant individuals. The IL-GH1 population was collected from a greenhouse where insecticides, including spinosad, were routinely applied. The spray histories of the other greenhouses where colonies were collected are unknown, but are likely to have included spinosad in rotation with other insecticides. None of the thrips populations collected from laboratory colonies or native populations in nonagricultural areas exhibited resistance to spinosad.

This study is the first to quantitatively document thrips resistance to spinosad in a greenhouse population. Survival of western flower thrips at the label rate of spinosad in a population collected from a greenhouse where spinosad was applied on average five times a year since March 1999 with up to eight applications occurring in a single year (records from IL-GH1) may indicate that misuse of this insecticide will produce resistant thrips populations as the genes conferring resistance to spinosad may not be rare in certain insect populations (Moulton et al., 2000). Presently, an effective replacement for spinosad is unavailable. Resistance to an insecticide, such as spinosad, with a novel mode of action and the lack of an effective replacement increases the importance of developing rotation programs that may preserve the longevity of currently existing insecticides. In addition to rotating insecticides with different modes of activity and properly applying currently available insecticides, alternative methods to manage western flower thrips must be identified and incorporated into greenhouse crop production systems.

\section{Literature Cited}

Agresti, A. 2002. Categorical data analysis. John Wiley and Sons, Hoboken, N.J.

Broadbent, A.B. and D.J. Pree. 1997. Resistance to insecticides in populations of Frankliniella occidentalis (Pergande) (Thysanoptera: Thripidae) from greenhouses in the Niagara region of Ontario. Can. Entomol. 129:907-913.

Brødsgaard, H.F. 1994. Insecticide resistance in European and African strains of western flower thrips (Thysanoptera: Thripidae) tested in a new residue-on-glass test. J. Econ. Entomol. 87:1141-1146.

Cloyd, R.A., D.F. Warnock, and K. Holmes. 2001. Technique for collecting thrips for use in insecticide efficacy trials. HortScience 36:925-926.

Cloyd, R.A. and C.S. Sadof. 2000. Effects of spinosad and acephate on western flower thrips inside and outside a greenhouse. HortTechnology 10:359-362

Eger, Jr., J.E., J. Stavisky, and J.E. Funderburk. 1998. Comparative toxicity of spinosad to Frankliniella spp. (Thysanoptera: Thripidae), with notes on a bioassay technique. Fla. Entomol. 81:547-551.

Immaraju, J.A., T.D. Paine, J.A. Bethke, K.L. Robb, and J.P. Newman. 1992. Western flower thrips (Thysanoptera: Thripidae) resistance to insecticides in coastal California greenhouses. J. Econ. Entomol. 85:9-14.

Lewis, T. 1997. Pest thrips in perspective, p. 1-13. In: T. Lewis (ed.). Thrips as crop pests. University Press, Cambridge, U.K.

Lublinkhof, J. and D.E. Foster. 1977. Development and reproductive capacity of Frankliniella occidentalis (Thysanoptera: Thripidae) reared at three temperatures. J. Kans. Entomol. Soc. 50:313-316.

Moulton, J.K., D.A. Pepper, and T.J. Dennehy. 2000. Beet armyworm (Spodoptera exigua) resistance to spinosad. Pest Management Sci. 56:842-848.

Parrella, M.P. 1995. IPM-Approaches and prospects, p. 357-363. In: B. Parker, M. Skinner, and T. Lewis (eds.). Thrips biology and management. Plenum Press, New York.

Roe, R.M., W.D. Bailey, H.P. Young, C.F. Wyss, and P. Dugger. 2000. Characterization of spinosad $\left(\right.$ Tracer $\left.{ }^{\circledR}\right)$ resistance in a laboratory strain of the tobacco budworm and development of novel diagnostics for resistance monitoring in the field, p. 926-929. In: D. Richter (ed.). 2000 Proceedings beltwide cotton conferences, San Antonio, Texas, 4-8 Jan. 2000. National Cotton Council, Memphis, Tenn.

Salgado, V.L. 1998. Studies on the mode of action of spinosad: Insect symptoms and physiological correlates. Pesticide Biochem. Physiol. 60:91-102.

Ullman, D.E., J.L. Sherwood, and T.L. German. 1997. Thrips as vectors of plant pathogens, $p$. 539-565. In: T. Lewis (ed.). Thrips as crop pests. Univ. Press, Cambridge, U.K.

Westergren, A., S. Karlsson, P. Andersson, O. Ohlsson, and I.R. Hallberg. 2001. Eating difficulties, need for assisted eating, nutritional status and pressure ulcers in patients admitted for stroke rehabilitation. J. Clinical Nursing 10:257-269.

Wyss, C.F., H.P. Young, J. Shukla, and R.M. Roe. 2003. Biology and genetics of a laboratory strain of the tobacco budworm, Heliothis virescens (Lepidoptera: Noctuidae), highly resistant to spinosad. Crop Protection 22:307-314.

Young, H.P., W.D. Bailey, and R.M. Roe. 2003. Spinosad selection of a laboratory strain of tobacco budworm, Heliothis virescens (Lepidoptera: Noctuidae), and characterization of resistance. Crop Protection 22:265-273.

Zhao, G., W. Liu, J.M. Brown, and C.O. Knowles. 1995. Insecticide resistance in field and laboratory strains of western flower thrips (Thysanoptera: Thripidae). J. Econ. Entomol. 88:1164-1170.

Zhao, J.Z., Y.X. Li, H.L. Collins, L. GusukumaMinuto, R.F.L. Mau, G.D. Thompson, and A.M. Shelton. 2002. Monitoring and characterization of diamondback moth (Lepidoptera: Plutellidae) resistance to spinosad. J. Econ. Entomol. 95: 430-436. 